\title{
Enjoying working and learning in vocational education: a multilevel investigation of emotional crossover and contextual moderators
}

\author{
Julia Warwas $^{1^{*}}$ and Christoph Helm²
}

\section{${ }^{*}$ Correspondence:}

julia.warwas@uni-bamberg. de

${ }^{1}$ Chair of Business

Education and Educational Management, University of Bamberg, Kärntenstr. 7, 96052 Bamberg, Germany Full list of author information is available at the end of the article

\begin{abstract}
Background: Students' positive emotions, such as enjoying learning activities at school, are increasingly recognized as being conducive to learning. Researchers therefore seek to understand the roles that teachers' emotions and instructional behaviours play for promoting activity-related enjoyment among their students. This study is the first to investigate emotional crossover in vocational classrooms, combining ControlValue Theory and Broaden-and-Built Theory to substantiate potentially mediating teaching characteristics (clarity and support, enthusiastic teaching, application-orientation). Moreover, this study explores contextual moderators of crossover by comparing different types of training (classes in dual and in school-based training programs) as well as different domains of training (commercial, technical, and social occupations).

Methods: Survey data were gathered from 77 teachers and 1522 students with a temporal distance of about 5 months, covering a considerable period of instructional interaction. Data were examined with multilevel latent contextual models, which allow controlling for measurement and sampling errors as well as for potential confounders when testing mediation and moderated mediation in nested data structures.
\end{abstract}

Results and conclusions: Mediation analysis for the full sample indicates substantial positive relations between (a) teachers' work enjoyment and teaching characteristics, and between (b) teaching characteristics and students' enjoyment of lessons. Still, crossover of activity-related emotions cannot be empirically established. Moderator analyses reveal that crossover occurrence is not a function of training type. However, positive relations between teaching characteristics and students' enjoyment vary in strength across the three contrasted vocational domains, and the same applies to positive associations between teachers' enjoyment and teaching characteristics. Consequently, crossover effects are demonstrable only in commercial classes. The paper therefore discusses methodological issues, further research needs and practical implications.

Keywords: Teacher emotions, Student emotions, Work enjoyment, Learning enjoyment, Teaching characteristics, Emotional crossover, Multilevel latent contextual models, Vocational schools 


\section{Background}

Over the last decade, research on student emotions has provided substantial evidence on the viable functions that positive emotions during learning activities play for learning processes and outcomes (Valiente et al. 2012). Recurring experiences of positive activityrelated emotions such as enjoyment promote students' interest, effort and engagement (e.g., Ainley and Ainley 2011; Reyes et al. 2012), strengthen the use of in-depth learning strategies, including critical thinking, elaboration and self-monitoring (e.g., Ahmed et al. 2013), and in so doing, enhance students' academic performance (e.g., Buff et al. 2011; Ranellucci et al. 2015).

In the wake of these findings, researchers increasingly focus on instructional features that foster positive emotions (e.g., Gläser-Zikuda et al. 2005; Seifried and Sembill 2005). One recent explanation argues that students' enjoyment of learning activities is at least partly influenced by teachers' enjoyment of their professional practice, and that teachers' instructional behaviours function as mediators (Frenzel 2014; Kunter and Holzberger 2014). This explanation draws attention to the interplay of emotions experienced by different individuals within a shared social environment (Westman 2006). In principle, emotional crossover denotes a process in which discrete emotions or even complex psychological phenomena such as stress are transmitted from one person to another or to a group via social interaction (Härtel and Page 2009; Bakker et al. 2009). Thus, individual emotions systematically affect those of interaction partners, as has been demonstrated for team leaders and team staff (e.g., Sy et al. 2005). Yet empirical examinations of emotional crossover from teachers to students are still scarce and confined to classrooms in the general (non-vocational) education system, leaving open to question whether findings can be generalized to other educational settings (Meyer 2014).

To address this blind spot, the present study aims to test assumptions on emotional crossover in vocational school classes. More precisely, we examine how teachers' positive emotions towards their professional practice (work enjoyment) relate to their instructional behaviours (teaching characteristics) and to students' positive emotions towards learning activities in class (enjoyment of lessons). The study employs a survey design with two measurement points, connecting teacher reports of work enjoyment at the beginning of the school year $(\mathrm{N}=77)$ to student ratings of their teachers' instructional behaviours and the extent to which they generally enjoy lessons about 5 months later $(\mathrm{N}=1522)$. The fact that questionnaire data were collected from different informants and at disparate points in time makes this study less susceptible to common source bias than many previous studies (see Frenzel 2014 for a critical review). Regarding the focal psychological constructs, it is important to note, however, that this study does not investigate continual fluctuations of emotional experiences that occur within each student in the course of a lesson. Rather than tracking intra-individual changes of transient emotional states such as passing delight over singular events, we aim at explaining betweenclass differences in students' prevalent, habitual emotions. Simply put, we focus on the overall emotional "tone" or "climate" among class members that dominates most of the lessons over a longer period of instructional interaction (Frenzel et al. 2009a; Reyes et al. 2012). Trait-like emotions such as habitual enjoyment of learning activities differ from momentary and dynamic state emotions not only regarding their major impact on developing and maintaining interest in subject matter (Ainley and Ainley 2011) but 
also regarding their superior predictive power for future choices and actions (Wirtz et al. 2003; Levine et al. 2009). Moreover, both psychological constructs need adequate strategies of measurement (Bieg et al. 2014). Whereas process-oriented strategies such as Continuous State Sampling are mandatory to capture transient emotional states, retrospective reports on how much enjoyment students usually felt during the past school semester are more suitable to assess their habitual, prevalent emotional experiences.

Demonstrable consequences of learners' habitual emotions on learning strategies and outcomes make them interesting objects of study in any educational system (Hascher 2010). However, in Germany's complex system of vocational education, covering more than 300 training occupations, program structures as well as contents and target groups of instruction vary greatly between classrooms (e.g., Hoeckel and Schwartz 2010). Therefore, the second objective of our study is to explore possible differential relationships of teachers' emotions and instructional behaviours with their student emotions, depending on the structural contexts in which they unfold. Among the multitude of potential moderators, we examine the formal type of initial vocational training by distinguishing classes that belong to fully school-based training programs from classes in 'dual' training programs. We further examine occupational fields, which delineate target groups and content domains in vocational education (BIBB 2016), by comparing classes that prepare for commercial, technical, or social careers. To gain empirical insights into these issues, we estimate multilevel contextual models that allow investigating mediation and moderated mediation on the class level while controlling for measurement and sampling errors as well as for potential confounders of enjoyment ratings at the student level.

\section{A basic explanatory model of enjoyment crossover from teachers to students Distinctive features of enjoyment}

Emotions are multimodal but highly integrated phenomena of processing one's interaction with the social and material environment (Scherer 2005). Enjoyment typically features high (neuro-) physiological arousal, known as $\beta$-adrenergic sympathetic activation, which comprises, for example, demonstrable increases in heart rate, heart rate variability, systolic blood pressure and respiration rate (Kreibig 2010). Its expressive components most notably include enjoyment smiles, which serve as reliable markers of trustworthiness and cooperative intent (Johnston et al. 2010). However, subjective feelings that take over internal monitoring and signalling functions lie at the heart of an emotional experience.

Subjective feelings integrate the total pattern of an emotional reaction, are typically accessible to conscious awareness and can therefore be put into words (Scherer 2005). In this respect, enjoyment denotes feelings of confidence, vigour, pleasure and a sense of eagerness and meaningfulness when engaging in an activity (Ainley and Ainley 2011; Izard 1977). At school, students who enjoy learning typically "feel excited when tackling the task, appraise the task as challenging, experience physiological arousal" and feel "motivated to work at the task" (Pekrun et al. 2002, p. 155). Similarly, contemporary research on dispositional teacher enthusiasm suggests that teachers who are enthusiastic about their work habitually feel "enjoyment, pleasure and excitement" and gladly display these feelings when performing professional practices (Keller et al. 2014, p. 30). 
Yet, the possibility that teachers' enjoyment might transfer to their students has hardly been investigated (Becker et al. 2014). According to Frenzel's (2014) review of research, an indirect pathway, often referred to as emotional crossover, seems to be particularly suitable to explain such processes.

\section{Mechanisms and mediators of transmitting enjoyment}

Indirect emotional crossover relies on complex social behaviours that occupy a mediating position (Westman 2006) - a feature that most notably delineates crossover effects from predominantly automated mechanisms of immediate emotional contagion (Hatfield et al. 2014). Contagious effects comprise of ubiquitous, culturally invariant tendencies of behavioural mimicry (see also Chartrand et al. 2005), followed by afferent feedback. By mimicking, people continuously synchronize the facial expressions, vocal productions, postures, gestures and movements displayed by an interaction partner. Through afferent feedback, somatic and visceral sensations such as muscular tension or cardiac palpitation travel to the central nervous system where they are subjected to cortical processing (Aziz et al. 2000). Thus, behavioural synchrony of interaction partners, regarding overt bodily symptoms of emoting, fosters emotional convergence, regarding associated subjective feelings. By contrast, the social interactions that function as the "transmission belts" of emotional crossover are culturally shaped and context-specific. This necessitates theoretical considerations as to which mediating behaviours are relevant for transmitting particular emotional qualities within a given social environment (Becker et al. 2014).

Teaching characteristics that may mediate the transfer of positive activity-related emotions from teachers to students in a classroom setting should meet two requirements, set out in the following sections. They should be likely to prompt students' appraisals of instruction that elicit feelings of enjoying a lesson but also vary systematically by teachers' levels of enjoying their professional practice.

According to Ellsworth and Scherer's (2003) emotion-specific appraisal profiles, enjoyment emerges whenever high coping potential coincides with high intrinsic pleasure and high goal conduciveness. Correspondingly, Control-Value Theory of achievement emotions (e.g., Pekrun et al. 2007) posits that students enjoy learning when they are confident to master subject matter while they attribute intrinsic and/or extrinsic value to the tasks, materials and contents at hand. Value attributions occur when students evaluate their engagement with tasks, materials and contents as inherently pleasurable and/ or instrumentally useful for attaining further-reaching goals, for example, a successful graduation.

In line with this reasoning and previous studies that examined links between teaching characteristics and student emotions, we expect teachers' communicative clarity and individualized support to foster students' enjoyment of lessons, because, implicitly, these features foster students' control appraisals (e.g., Goetz et al. 2013; Hagenauer and Hascher 2010; Titsworth et al. 2013). By providing comprehensible explanations, by using illustrative examples and plain language, and by assisting to overcome individual difficulties with feedback, hints and encouragement, teachers can strengthen students' expectations to cope successfully with instructional demands. 
Furthermore, we expect an enthusiastic teaching style and application-oriented instruction to enhance students' enjoyment, because, implicitly, both reinforce attributions of value to instructional tasks, materials and contents. Teachers who demonstrate fascination about subject matter, use humour, vivid expressions and gestures, employ varied methods and incorporate students' interests and ideas allow students to experience that dealing with subject matter can be pleasurable (Brophy 2008). ${ }^{1}$ Teachers who generate authentic learning environments by connecting subject matter to operational processes in the students' occupational field should further strengthen students' impressions that they will benefit from knowledge and skills they acquire at school when dealing with tasks and problems at their future workplaces (De Bruijn and Leeman 2011; Sembill et al. 2007).

Mood research and positive psychology justify the assumption that teachers' own levels of work enjoyment influence the extent to which they provide clarity and support, stimulation and application-orientation. Fredrickson and Branigan (2005) conclude from numerous studies that positive emotions broaden thought-action repertoires. That is, positive emotions widen the scope of attention and perception, facilitate elaborate, flexible and integrative ways of processing information and enable people to develop a rich set of action alternatives. Experimental evidence further suggests that people experiencing positive emotions show more fairness, kindness and helpfulness towards others and adopt more socially responsible approaches to solving problems than controls (Isen 2008). Thus, it seems reasonable to expect teachers who predominantly enjoy their work to draw upon a broad array of teaching strategies, allowing them higher levels of creativity, variety and flexibility than colleagues with low levels of work enjoyment. Additionally, they could also be more attentive and sensitive to individual learning difficulties and more likely to give encouragement and assistance when needed (see also Frenzel 2014).

Indeed, studies investigating relations between teacher emotions and perceived teaching characteristics suggest that "joyful" teachers offer more cognitively stimulating and coherent lessons, grant more room for student activities and questions and provide more exciting lectures (Frenzel et al. 2009b). In a similar vein, teachers' self-reported enthusiasm for teaching was found to relate to student ratings of monitoring, cognitive challenge and social support (Kunter et al. 2008).

\section{Extant evidence of emotional crossover from teachers to students via teaching characteristics}

Frenzel et al. (2009a) investigated emotional crossover in mathematics classrooms. Using a value-added strategy to analyse questionnaire data from teachers $(\mathrm{N}=71)$ and students $(\mathrm{N}=1542)$, they detected a positive association between students' and teachers' habitual levels of enjoyment (both available for grade 8), even after adjusting for students' enjoyment in the previous school year (reported in grade 7). Results from multilevel models further suggest that this association was established via observable facets of enthusiastic teaching behaviour (assessed by students in grade 8).

\footnotetext{
${ }^{1}$ It is worth mentioning that in the case of enthusiastic teaching, simple bodily expressions that typically trigger contagious effects (such as smiling), and more complex social behaviors that form the basis of crossover effects (such as making humorous remarks), overlap. Very often, an inclusive relation exists, with enthusiastic teaching behaviors embracing automated expressive components of an emotional experience (Keller et al. 2014). However, enthusiastic teaching as a multifaceted phenomenon goes beyond bodily symptoms and includes, for instance, varied presentational forms.
} 
Becker et al. (2014) analysed experience-sampling data from 149 students in grade 9 classes, who rated their teachers' emotions (joy, anger and anxiety), instructional behaviours and their own emotions during 15 lessons in four academic subjects. Perceived understandability and lesson structure as well as perceived practical relevance of instructional contents were positively related to students' enjoyment of lessons. Perceived teacher emotions additionally contributed to explaining intra-individual variations of students' state emotions during instructional interaction.

Both studies provide valuable insights into the interplay of teacher and student emotions that exists in rather homogeneous classes of the secondary school track. Now the question arises how much we may generalize from these findings. Do assumed positive relations also apply to vocational classes, and do they apply across differing contextual conditions of instructional interaction?

\section{Varied conditions for instructional interaction in vocational classrooms}

Germany's system of initial vocational training does not represent a uniform system. To the contrary, it embraces two types of institutionalized training programs that fundamentally differ with respect to the amount of schooling and students' involvement in workplace learning. Students who complete a dual vocational program predominantly receive practical, in-firm training, draw a regular salary and are closely integrated in operational procedures and collegial cooperation of their training company. Complementarily, they visit a vocational school, where they receive theoretical instruction for about $12 \mathrm{~h}$ per week or 1 week per month (Deissinger and Hellwig 2005). Other students enrol in primarily school-based training programs, which may contain a temporary internship period (Deissinger 2007). Attending either a dual or a fully school-based training program obviously affects the time students spend in vocational classrooms and, thus, the mere number of occasions in which they can observe vocational teachers' instructional behaviours and participate in instructional interaction. It also affects the continuity of their learning experiences in the classroom. But to our knowledge, theoretical assumptions and comparative investigations on learning-related emotions under differing training conditions are lacking.

Furthermore, vocational classrooms vary greatly with respect to instructional contents and learner groups. Very basically, we can distinguish classes for commercial, technical, and social fields of occupation, preparing students to become, for instance, bank clerks, mechanics or paediatric nurses. All of these classes offer highly distinct, targeted instruction in line with occupation-specific curricula (BIBB 2016; Hoeckel and Schwartz 2010). Previous studies suggest that perceived characteristics of instructional interaction differentially affect vocational students' intrinsic learning motivation, depending on students' occupational field. Whereas perceived autonomy, competence and social relatedness were prognostically most important in commercial classes (e.g., Helm 2015), perceived content relevance, instructional clarity and level of difficulty were the main predictors in technical classes (Knöll et al. 2007). Following Eder's (2006) study on person-environment congruence in Austria's upper secondary school system, schools that offer vocationally oriented education but specialize in distinct occupational fields create different learning environments to match and promote their students' differing aptitudes and interests. Whereas commercial schools attract students with enterprising, 
conventional, and artistic interests, technical schools mostly include students with realistic, investigative, and conventional interests, and social schools contain students who mainly pursue social, artistic, and enterprising interests.

Thus, against the current lack of studies on emotional crossover in vocational classrooms, available findings on diverging interests of students in distinct segments of vocational education and on their partially differing evaluations of instructional features caution us to consider domain-specific variations. Consequently, we integrate occupational fields (indicating distinct contents and target groups of training) as potential moderators of crossover relations in vocational classes.

\section{Students' self-related beliefs as confounders of their habitual learning-related emotions}

When analysing how features of class-specific learning environments (i.e., enjoyment levels and instructional behaviours of teachers) relate to class members' habitual, recurring emotions during a longer period of instructional interaction, it is advisable to control for student-specific differences in recalling emotions, which span diverse environments and vary among the learners, irrespective of class membership. Very basically, Robinson and Clore's Accessibility model of emotional self-reports argues that retrospective ratings of habitual emotions are not only informed by characteristics of the environment in which they occurred (or rather, their reflections in episodic memory) but also shaped by a person's identity-relevant beliefs (i.e., semantic knowledge about oneself and one's general relation with that environment).

More specifically, Control-Value Theory posits that a person's sense of self-efficacy directly influences the frequency and intensity of experiencing positive emotions in achievement contexts, causing students with strong efficacy beliefs to enjoy learning activities more often than those who lack confidence in their own abilities (Pekrun et al. 2007). Academic self-efficacy regarding school-related skills and abilities thus denotes relatively stable and generalized beliefs of students that blend all their past learning experiences at school-across different situations, subjects, and classes (e.g., Putwain et al. 2013). This conviction of being able to master even demanding learning tasks at school demonstrably biases students' self-reported levels of enjoyment during classroom instruction (Bieg et al. 2014; Goetz et al. 2010). With the purpose of identifying the net associations of class-level factors with students' habitual enjoyment of lessons, we therefore estimate multilevel models that include academic self-efficacy as an independent variable at the student level. That way, we can adjust for the generalized self-efficacy bias in students' ratings of the enjoyment they habitually experience during a specific teacher's lessons.

\section{Assumptions}

Building on the theoretical considerations and empirical evidence outlined in chapter 2 ("A basic model...") and 4 ("Students' self-related beliefs..."), the present study on emotional crossover in vocational classrooms aims to test the following assumptions.

H1: In line with Broaden-and-Build Theory, teachers' work enjoyment should positively relate to the extent of communicative clarity, individualized support, enthusiastic teaching and application orientation they provide during instruction. 
H2: According to Control-Value Theory, the teaching characteristics listed in H1 should positively relate to students' levels of enjoying the lessons.

H3: Consistent with explanatory models of emotional crossover, teachers' enjoyment should be associated with students' enjoyment via observable teaching characteristics.

H4: Each student's generalized beliefs of academic self-efficacy should positively relate to his/her individual level of enjoying the lessons.

In view of the structurally varied conditions of teaching and learning in vocational classrooms, outlined in chapter 3 ("Varied conditions..."), the present study further aims to examine if crossover occurrence or strength depends on either the type of training program (fully school-based or dual, i.e., complementing in-firm training), or on the domain of training (which delineates contents and target groups based on occupational fields). Since crossover theory does not particularly attend to classroom contexts (Bakker et al. 2009) and reference studies on our topic are missing, we follow a largely exploratory approach. However, in addition to reported empirical evidence on vocational students' interests and learning motivation, there are also theoretical reasons to examine potentially varying strengths of relationships between teaching characteristics and students' enjoyment under differing contextual conditions of instructional interaction. Pekrun and Stephens (2010, p. 250) propose for testing Control-Value Theory across heterogeneous achievement contexts: “The basic structures and causal mechanisms of achievement emotions are expected to follow nomothetic principles, whereas reference objects, intensity, and duration of emotions can differ".

Following this rationale, we expect teaching characteristics that assumedly enhance students' appraisals of coping potential, inherent pleasure and instrumental utility to be generally beneficial to students' enjoyment of lessons (Bieg et al. 2013; section on "Mechanisms and mediators..."). However, their relative significance for eliciting feelings of enjoyment and, thus, the strength of these positive relations may vary between occupational fields and/or types of training. ${ }^{2}$

\section{Methods}

\section{Statistical analysis, model evaluation and interpretation of effect sizes}

To examine these issues, we take two steps: First, we specify multilevel structural equation models for each indirect effect of $\mathrm{H} 3$, which allows us to test the direct effects described in $\mathrm{H} 1$ and $\mathrm{H} 2$ concurrently. We adopt a doubly latent approach to estimate class-specific parameters, thereby controlling for both measurement and sampling errors (Marsh et al. 2009). Second, we perform two multilevel multigroup comparisons to test the potentially moderating effects of the categorical variables training type and training domain (i.e., occupational field). Additional file 1: Tables SA, SB demonstrate measurement invariance

\footnotetext{
2 This does not contradict assumptions on structurally equivalent instruction-enjoyment relations across different academic subjects WITHIN individual students. Extant investigations of rather homogeneous classroom contexts in general compulsory education suggest that intra-individual relations between perceived teaching characteristics and momentary emotional states are largely consistent across common subject domains such as language or mathematics instruction (e.g., Goetz et al. 2013). Interestingly, feelings of (state) enjoyment seem to form a notable exception to this rule (Becker et al. 2014).
} 
(MI) for almost all constructs, as indicated by the non-significant reduction of the model fit index CFI (<.020) when testing a more restricted model (strong MI) against the less restricted one (weak MI) (Chen 2007; Cheung and Rensvold 2002). Except for work enjoyment, configural, metric and scalar invariance exists across all moderator groups. Minor restrictions for the work enjoyment scale may be due to the small number of teachers in each of the compared groups (see "Sample"). Nevertheless, the measurement model does not perfectly match the data in the commercial and the technical subgroup. We will be aware of that deficit when discussing results and limitations of our study.

We used Mplus 7.3 (Muthén and Muthén 1998-2014) to estimate all models. Model constraint commands proposed by Stride et al. (2015) served to calculate indirect and total effects. Model fits were evaluated based on Comparative Fit Index (CFI), Tucker Lewis Index (TLI), Root Mean Square Error of Approximation (RMSEA) and Standardized Root Mean Square Residual (SRMR). According to Hu and Bentler (1999) and Little (2013), values of CFI $\geq .95 / .90$, TLI $\geq .95 / .90$, RMSEA $\leq .05 / .08$, and SRMR $\leq .05 / .10$ indicate good/acceptable fit.

The small level-2 cluster size $(\mathrm{N}=77)$ reduces power to establish statistically significant associations between the investigated constructs as well as significant differences between the comparison groups. Therefore, we additionally refer to effect sizes and focus on regression coefficients larger than one-third of the standard deviation of classlevel constructs (i.e., in the class-level part of the respective doubly latent variables). Since standard deviations in our sample reach up to .598 , we consider $\mathrm{b}$ and $\Delta \mathrm{b}>.200$ as evidence supporting our hypotheses. Reports of unstandardized regression coefficients are common practice when testing moderation by way of multigroup comparisons. The reason for this lies in the fact that the standard deviations are usually not equal among the compared groups. Because standard deviations of both the independent and the dependent variables are used to convert unstandardized into standardized coefficients, differing standard deviations may lead to unequal standardized coefficients between groups, even in the case of equal unstandardized coefficients. Indeed, even if models are specified such that structural paths are constrained to be equal between groups, the comparison of standardized coefficients can yield artificial differences that are due to differing standard deviations between groups and not to true moderation. In the present paper, we thus use unstandardized coefficients to report moderated associations but also to document direct and mediated associations in order to ensure consistency throughout all tables and figures. That way, we additionally avoid overestimating expected positive relations. Owing to moderate between-class variability, the standardized coefficients available for mediation models in Mplus are indeed very high for our variables (on average, $\beta=.7$ for relations of teaching characteristics with students' enjoyment of lessons).

\section{Sample}

In line with previous studies and theoretical assumptions about the integrating and signalling functions of subjective feelings ("Distinctive features of enjoyment"), questionnaires served to assess teacher and student emotions. Surveys were conducted in 77 vocational classes in 27 vocational schools that are located in Bavaria/Germany. Students in each class rated exactly one teacher, and no teacher was rated twice. Thus, data stem from 77 different teachers $(57.1 \%$ male; seniority $M=17.68$; $S D=9.22)$ and a total 
of 1522 students ( $40.9 \%$ male; $71.6 \%$ between 17 and 20 years old; $12.9 \%$ younger than 17 years; $15.4 \%$ older than 20 years).

31 classes prepare for social, particularly for pedagogical and caring occupations (592 students); 22 classes prepare for commercial occupations (454 students); 24 classes prepare for technical occupations (476 students). A total of 598 students (in 29 classes) undergo a fully school-based training; 924 students (in 48 classes) belong to the dual track of vocational training.

Teachers had no missing values on any item. Missing values in student questionnaires ranged between .1 and $2.2 \%$ per rating item, with Little's Chi square test indicating that they were missing completely at random $\left(\mathrm{x}^{2}=1197.683\right.$; $\left.\mathrm{df}=1181 ; \mathrm{p}=.361\right)$. These items were imputed with the expectation-maximization algorithm.

\section{Measures}

Questionnaires for teachers and students were adapted from previous studies on teachers' job attitudes and instructional quality (see Additional file 1: Table SE) and administered with a temporal distance of around 5 months. We examined the factorial structure of teaching characteristics through Chi square difference tests with the Satorra-Bentler scaled Chi square. A 1-factor model performed substantially worse than a 3-factor model ( TRd $=25.172, \mathrm{df}=3, \mathrm{p}=.000)$, indicating that "clarity and support", "enthusiastic teaching", and "application orientation", represent conceptually and empirically distinct constructs. Table 1 provides descriptive statistics, reliability measures and sample items for all scales. Table 2 summarizes model fit indices for confirmatory factor analyses and doubly latent models. Cronbach's Alphas and ICC(2)-values above the conventional cut off of .70 indicate that internal consistencies of each scale and reliabilities of all aggregate constructs are at least satisfying (Lüdtke et al. 2009). In addition, relative fit measures $($ CFI, TLI > .95) and absolute fit measures (RMSEA $<.08$, SRMR $<.10)$ suggest that most estimated models reproduce the data well. Only the doubly latent model for student enjoyment does not fully meet these requirements. However, RMSEA and SRMR tend to be high (biased) with small samples in general. ICC(1)-values for latent class-level

Table 1 Descriptive statistics and reliability measures for all variables

\begin{tabular}{|c|c|c|c|c|c|c|c|}
\hline Measures & \# Items & M & SD & Alpha & $\operatorname{ICC}(1)$ & $\operatorname{ICC}(2)$ & Sample item \\
\hline Clarity and support & 7 & 4.61 & 1.00 & .90 & .23 & .88 & $\begin{array}{l}\text { Our teacher explains concepts thor- } \\
\text { oughly } \\
\text { Our teacher supports students who } \\
\text { have difficulties understanding } \\
\text { subject matter }\end{array}$ \\
\hline Enthusiastic teaching & 4 & 3.74 & 1.19 & .88 & .16 & .74 & $\begin{array}{l}\text { Our teacher can excite us about subject } \\
\text { matter }\end{array}$ \\
\hline Application orientation & 3 & 4.16 & 1.24 & .87 & .16 & .83 & $\begin{array}{l}\text { Our teacher demonstrates the practical } \\
\text { usefulness of subject matter }\end{array}$ \\
\hline Enjoyment of lessons & 4 & 3.84 & .98 & .73 & .08 & .83 & During instruction, I usually feel joyful \\
\hline Academic self-efficacy & 4 & 4.66 & .86 & .78 & - & - & $\begin{array}{l}\text { When I make efforts, I can even solve } \\
\text { demanding learning tasks }\end{array}$ \\
\hline Work enjoyment & 6 & 4.94 & .79 & .81 & - & - & I truly enjoy my work! \\
\hline
\end{tabular}

A list of all items is presented in the Additional file 1

\# number, $M$ mean, SD standard deviation, ICC intraclass correlation coefficient 
Table 2 Model fit indices of doubly latent models (for aggregate constructs) and confirmatory factor analyses (for non-aggregate constructs)

\begin{tabular}{|c|c|c|c|c|c|c|c|c|c|}
\hline & N Par & $\mathrm{Chi}^{2}$ & $d f$ & $p$ & RMSEA & CFI & TLI & SRMR L1 & SRMR L2 \\
\hline \multicolumn{10}{|l|}{ Doubly latent } \\
\hline Clarity and support & 31 & 103.88 & 17 & .000 & .058 & .972 & .951 & .026 & .061 \\
\hline Enthusiastic teaching & 20 & 28.66 & 4 & .000 & .064 & .986 & .958 & .024 & .009 \\
\hline Application orientation & 14 & 1.36 & 1 & .244 & .015 & 1.000 & .998 & .001 & .006 \\
\hline Enjoyment of lessons & 20 & 69.56 & 4 & .000 & .104 & .956 & .868 & .012 & .165 \\
\hline \multicolumn{10}{|l|}{ CFA L1 } \\
\hline Academic self-efficacy & 13 & 2.47 & 1 & .116 & .031 & .998 & .990 & .007 & - \\
\hline \multicolumn{10}{|l|}{ CFA L2 } \\
\hline Work enjoyment & 19 & 8.02 & 8 & .432 & .001 & 1.000 & 1.000 & - & .046 \\
\hline
\end{tabular}

$N$ Par number of parameters, $d f$ degrees of freedom, $p \mathrm{p}$ value, RMSEA Root Mean Square Error of Approximation, CFI Comparative Fit Index, TLITucker Lewis Index, SRMR Standardized Root Mean Square Residual, L1 within, L2 between, CFA confirmatory factor analysis

constructs show substantial differences in the teachers' instructional behaviours ( $\geq 16 \%)$ but rather modest differences in students' enjoyment levels between classes (8\%).

\section{Results}

To test assumed emotional crossover and to investigate potential moderation by training type and training domain, we specified the models presented in Fig. 1. Teachers' work enjoyment represents the theoretically independent variable (IV), which is associated with three mediators (ME), named clarity and support (in Models M1/M4/M7), enthusiastic teaching (in Models M2/M5/M8), and application orientation (in Models M3/M6/ M9). These mediators in turn are related to students' enjoyment of lessons, which represents the theoretically dependent variable (DV). Figures 2 and 3 summarize the main findings, including estimated coefficients for indirect, total, and moderated mediation effects, which were calculated in accordance to the rules described in Fig. 1. Detailed results for all models are listed in Additional file 1: Table SC (fit indices) and Additional file 1: Table SD (regression coefficients and $\mathrm{p}$ values).

All models show acceptable fits with RMSEA values ranging from .044 to .054, CFI values ranging from .906 to .938 and TLI values ranging from .902 to .920 . SRMR-values slightly exceed the cut-off of .10, due to the small number of class-level clusters and the complexity of the doubly latent models. Nevertheless, the fact that independent variables in the mediation models explain up to $57 \%$ of variability in students' enjoyment again points to satisfactory model fit. According to Cohen (1988, 412 et seq.), the relevant $R^{2}$ values indicate large effect sizes.

In commenting our findings, we start with Models 1-3, which were calculated for the full sample. Consistent with H1, teachers' work enjoyment positively relates to their instructional behaviours, as rated by their students $(.237 \leq \mathrm{b} \geq .316)$. Conforming to $\mathrm{H} 2$, all perceived teaching characteristics in turn positively relate to students' enjoyment of the received lessons $(.278 \leq \mathrm{b} \geq .384)$. Nevertheless, our data do not confirm assumed mediated relations (H3). Neither indirect nor total effects are statistically significant or reach coefficients larger than .200 in the full sample. Correspondingly, the mediation models indicate that teachers' work enjoyment is not directly related to students' 


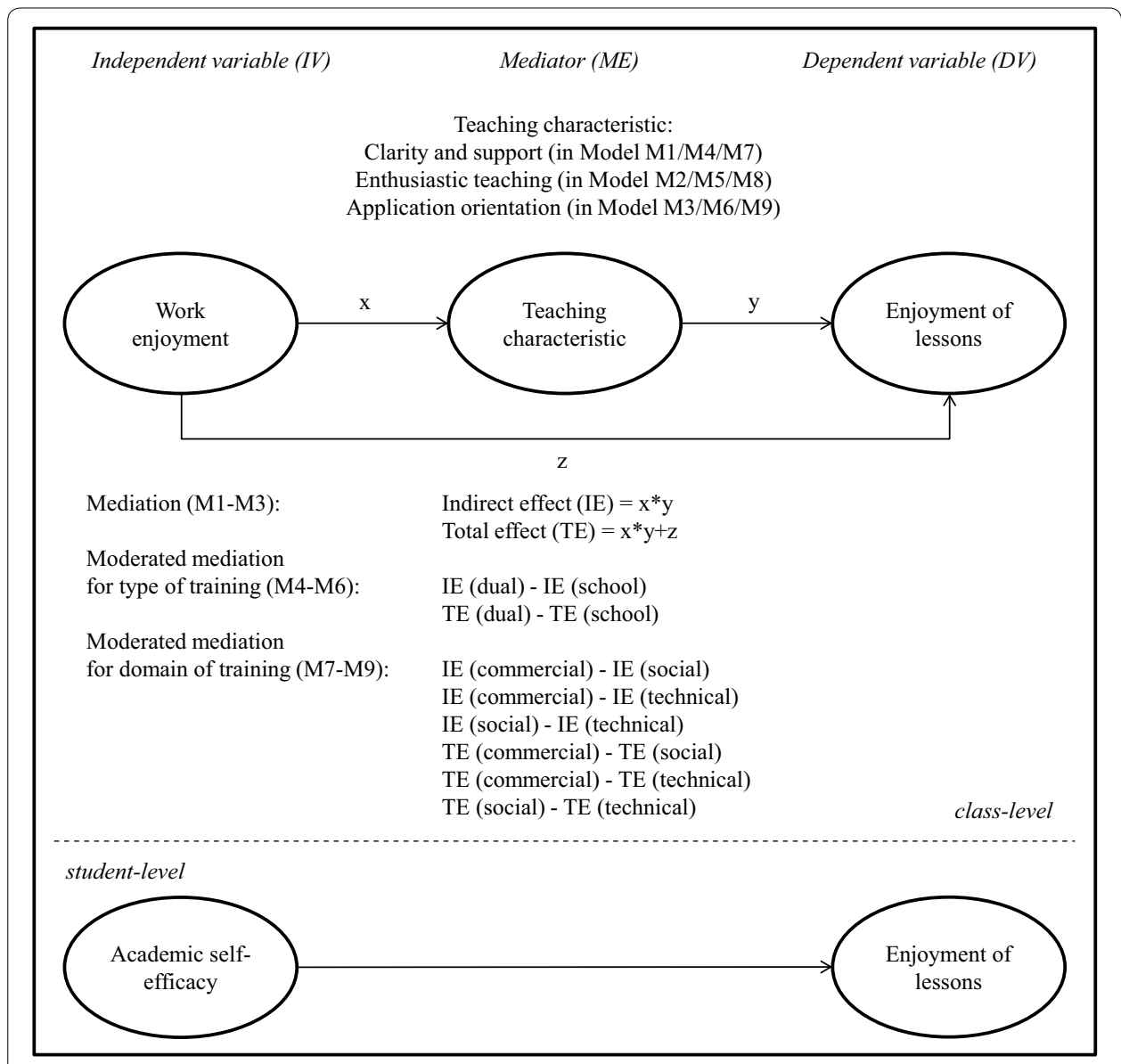

Fig. 1 Overview of specified mediation and moderated mediation models

enjoyment of lessons (ranging from $b=-.007$ to -.060 ). Additional analyses (not reported in the figure) reveal that this relation remains on a negligible level (i.e., with changed signs but still close to zero) even if mediators are excluded ( $b=.067, \mathrm{p}=.263$ )

Subsequently, we examined potential effects of categorical moderators by comparing subgroups. Our results do not indicate that the type of vocational training systematically alters the strength of relations between work enjoyment and teaching characteristics, or between teaching characteristics and lesson enjoyment (Models 4-6 in Additional file 1: Table SD). Thus, a separate figure is not provided. All estimated group differences fall below $\Delta \mathrm{b}=.200$ (see columns 9-12). Moreover, group-specific regression coefficients do not show a coherent pattern that might suggest consistently stronger relations under the condition of either a fully school-based training, or a dual training program (see columns 3-5).

However, some marked differences appear when comparing classes for social, commercial and technical occupations (Fig. 3). A closer look at the direct and total associations of teachers' enjoyment levels and instructional behaviours with class members' emotional experiences indeed suggests that in the investigated vocational classes, crossover occurrence is restricted to one occupational field (Models M7-M9 in Additional file 1: Table SD). 


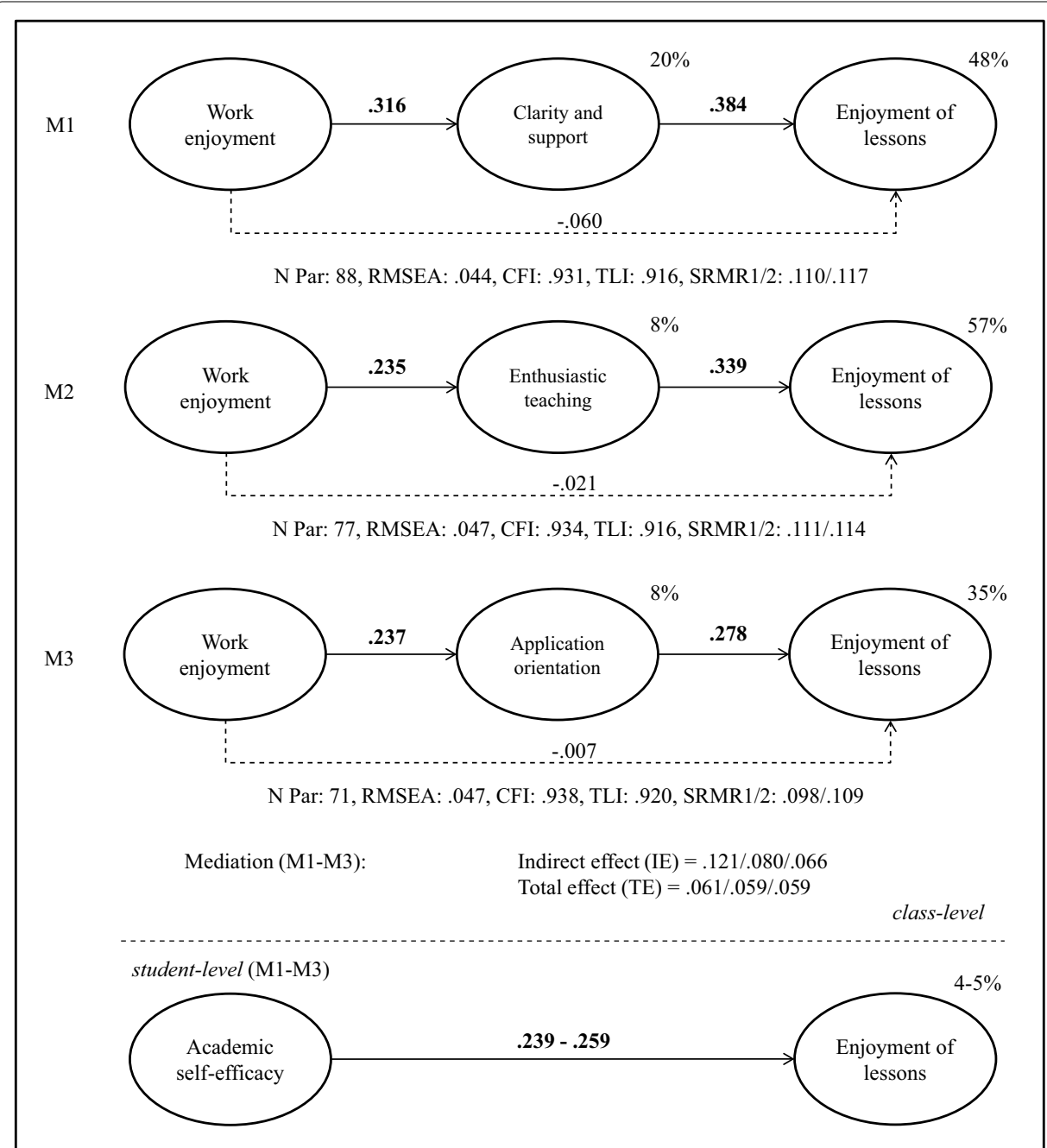

Fig. 2 Results for mediation models M1-M3 in the full sample ( $N=77$ classes). N Par number of parameters, RMSEA Root Mean Square Error of Approximation, CFI Comparative Fit Index, TLITucker Lewis Index, SRMR Standardized Root Mean Square Residual, SRMR1 SRMR within, SRMR2 SRMR between, values above ellipses: $R^{2}$. Coefficients larger than the cut-off $(>.200)$ are bold

\section{Work enjoyment $\rightarrow$ Teaching characteristics}

Relations of work enjoyment with clarity and support are considerably more pronounced among commercial and technical classes than among social classes $(\Delta \mathrm{b}=.421$, $\Delta \mathrm{b}=.324)$. Relations with enthusiastic teaching are considerably more pronounced among teachers in commercial classes than among teachers in social classes $(\Delta \mathrm{b}=.237)$.

\section{Teaching characteristics $\rightarrow$ Enjoyment of lessons}

Relations of clarity and support, enthusiastic teaching, and application orientation with students' enjoyment of lessons are all substantially stronger in social classes than in commercial and technical classes ( $\Delta \mathrm{b}$ ranging from -.288 to -.492 ). Further inspections of $\mathrm{b}$ values reinforce the impression that even though all teaching characteristics positively relate to students' enjoyment in each occupational field, the strength of associations varies. Whereas in social classes all three teaching characteristics are closely connected to 


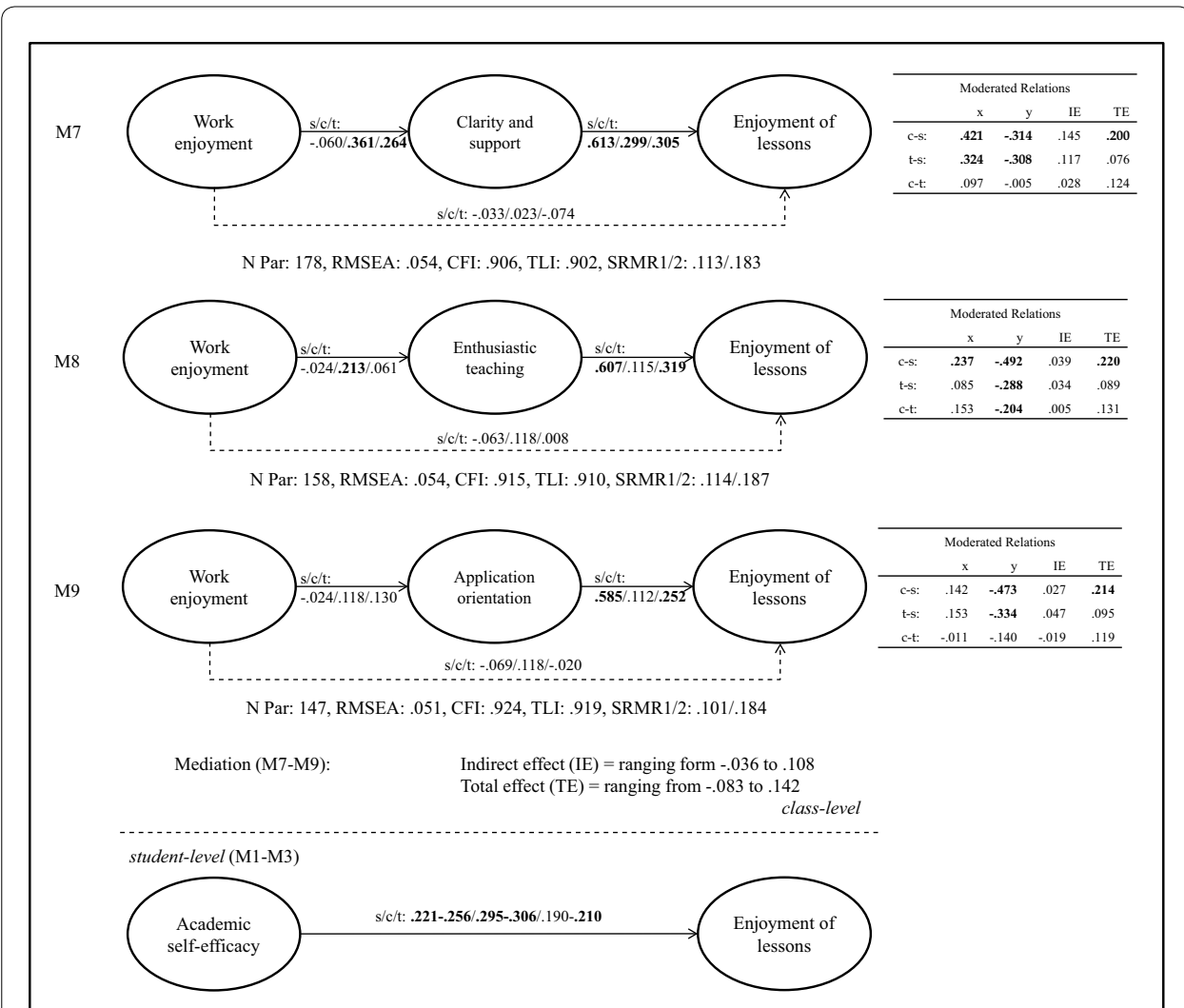

Fig. 3 Results for moderated mediation models M7-M9. N Par number of parameters, RMSEA Root Mean Square Error of Approximation, CFI Comparative Fit Index, TLITucker Lewis Index, SRMR Standardized Root Mean Square Residual, SRMR1 SRMR within, SRMR2 SRMR between, s social domain, c commercial domain, $t$ technical domain, $x$ path from work enjoyment to teaching characteristic, $y$ path from teaching characteristic to enjoyment of lessons. Coefficients larger than the cut-off (>.200) are bold

students' enjoyment $(.585 \leq \mathrm{b} \leq .613)$, commercial and technical students' enjoyment levels seem to depend only moderately on these characteristics $(.112 \leq \mathrm{b} \leq .319)$.

\section{Estimated total effects: work enjoyment $\rightarrow$ Enjoyment of lessons}

Crossover relations reach statistical significance at $\mathrm{p} \leq .10$ in commercial classes, where they are partially mediated by clarity and support: $\mathrm{b}=.131, \mathrm{p}=.035$, by enthusiastic teaching: $\mathrm{b}=.142, \mathrm{p}=.060$, and by application orientation: $\mathrm{b}=.131, \mathrm{p}=.106$ (see columns 7 and 12 in Additional file 1: Table SD for more details). Moreover, these effects are substantially larger than in social classes $(.200 \leq \Delta \mathrm{b} \leq .220)$. Mathematically, this finding arises from varying strengths of associations not only between teaching characteristics and lesson enjoyment but also between work enjoyment and teaching characteristics in the comparison groups. For example, instructional clarity and support proves to be a robust yet differently strong statistical predictor of students' positive emotions in all three occupational fields (M7: $.299 \leq \mathrm{b} \leq .613)$. But only in commercial and technical classes, the provision of clarity and support also systematically varies by the teachers' positive emotions $(\mathrm{b}=.361 / .264)$, with coefficients being considerably higher than in social classes $(\Delta \mathrm{b}=.421 / .324)$. Consequently, the combined magnitude of both associations (work enjoyment $\rightarrow$ clarity and support, and clarity and support $\rightarrow$ enjoyment 
of lessons), together with minor direct relations between teachers' and students' emotions, yields a systematic total effect in commercial classes $(\mathrm{b}=.131, \mathrm{p}=.035)$. Similarly, total effects of teachers' work enjoyment via enthusiastic teaching appear in commercial classes but just fail to reach statistical significance at a $p$ value of $.05(\mathrm{~b}=.142, \mathrm{p}=.060)$. In social classes, total effects are absent despite markedly stronger relations between all three teaching characteristics and students' enjoyment (see above), because in these classes, teachers' levels of work enjoyment are only loosely connected to their instructional behaviours.

All reported relations of class-specific constructs (i.e., teacher's work enjoyment and instructional behaviours) with class members' habitual emotions represent net associations, which remain after adjusting individual students' enjoyment levels for the biasing influence of academic self-efficacy. Conforming to H4, students' generalized beliefs of academic self-efficacy positively affect their answers on how much they usually enjoy the lessons (see column 13 in Additional file 1: Table SD).

\section{Discussion}

Two objectives guided the present study. The first was to test theoretical assumptions on the crossover of positive activity-related emotions from teachers to students in vocational classrooms. The second was to explore if crossover occurrence or strength may be conditional on the formal type of training (dual vs. school-based programs) or the domain of training (different occupational fields), which all co-exist in Germany's heterogeneous system of initial vocational training. By using multilevel latent contextual models (Marsh et al. 2009), we aimed to explain between-class variation regarding students' habitual enjoyment of lessons (rather than intra-individual variations in transient, momentary emotional states) while controlling for the confounding effects of academic self-efficacy beliefs on enjoyment ratings at the student level of analysis.

The full sample of 77 vocational classes (and correspondingly, 77 teachers) with altogether 1522 students served to investigate the first issue. Mediators were derived from appraisal-based theories of emotion elicitation and research in positive psychology ("Mechanism and mediators of transmitting enjoyment"). As expected, our data confirm substantial relations between work enjoyment reported by teachers and teaching characteristics perceived by students ( $\mathrm{H} 1)$ and between perceived teaching characteristics and student reports of enjoying the lessons ( $\mathrm{H} 2)$, after adjusting for the biasing influences of each student's generalized academic self-efficacy $(\mathrm{H} 4)$. Stated differently, the extent to which vocational students engage joyfully with subject matter demonstrably relates to teaching characteristics that implicitly prompt them to appraise learning activities as manageable (because of the teacher's communicative clarity and individualized support), inherently pleasurable (because of a stimulating, enthusiastic style of teaching), and instrumentally useful (due to an application-oriented instruction with respect to workplace demands). Moreover, most teachers who take much pleasure in their professional practice tend to display these characteristics to a higher degree than less enthusiastic colleagues do. This finding corresponds with the idea that recurring positive emotions should expand teachers' repertoire of instructional techniques, intensify their sensitivity to individual learning difficulties and increase their willingness to provide encouragement and assistance. Yet the absence of statistical mediation effects reinforces the 
impression that emotional crossover might depend on the training setting in which instructional interaction takes place.

Multilevel multigroup comparisons served to examine potential moderation by training type, but did not yield statistically or practically significant results. Thus, according to our data, crossover occurrence in vocational classrooms is not a function of the structural organisation of a training program such that, for example, crossover only happens in fully school-based training programs but not in dual training programs. However, we found systematic differences between distinct domains of training. Our results suggest that on the one hand, all three teaching characteristics positively relate to students' enjoyment levels while the strength of relationships varies across different target groups. Regression coefficients are substantially stronger in classes preparing for social occupations than in classes tailored to other domains. On the other hand, substantial positive relations of a teacher's work enjoyment with his/her instructional behaviours exist in commercial and technical classes but are absent in social classes. Consequently, significant total effects of vocational teachers' work enjoyment are demonstrable only in classes preparing for commercial occupations, where they operate mainly through communicative clarity and individualized support, and via enthusiastic teaching. Although the same instructional behaviours show even stronger relations with students' enjoyment in social classes, the extent to which teachers in social classes implement these behaviours seems to be decoupled from the extent to which they enjoy their work.

\section{Limitations and research implications}

Our unexpected finding that the relational strength between work enjoyment and teaching characteristics differs between teachers for distinct occupational areas leaves ample room for interpretation. We propose three possible reasons that may have created this result. To evaluate their accuracy, further investigations are needed.

One explanation lies in the conceptual breadth of teachers' work enjoyment, which does not exclusively pertain to instructional interaction. As Goetz et al. (2006) have demonstrated for students, the reference objects and experiential domains of individual enjoyment ratings can be narrowly or broadly defined, thereby forming an inclusive hierarchical structure of enjoying school in general and enjoying instructional interaction, homework, exams, and other aspects of school life in particular. Similarly, we can expect teachers' work enjoyment ratings to be largely informed by their instructional activities (which obviously are the central and most time-consuming part of the teaching profession) but also include other reference objects, such as collegial interactions, principal support, bureaucratic regulations, etc. Our data indicate that assuming measurement invariance of work enjoyment across teachers in different types and domains of training is not fully justified. Teachers in the compared groups may have attached slightly different meanings to the questionnaire items, some of them taking stock of all elements of their professional practice, others referring to a selected sphere of activity. Until now, studies that assess teachers' positive activity-related emotions for different reference objects in order to contrast their respective effects are extremely rare. Kunter et al. (2008) took first steps in this direction by distinguishing dispositional enthusiasm for teaching and for subject matter. Interestingly, systematic associations with instructional behaviours were only demonstrable for feeling enthusiastic about teaching but 
not subject matter. Therefore, we encourage researches to develop and apply differentiated measures of vocational teachers' activity-related enjoyment and to examine if these measures differentially affect instructional behaviours.

A second explanation focuses on school characteristics such as cooperation intensity among colleagues or with company trainers regarding instructional matters. Strong cooperative ties may partly compensate weak individual work enjoyment. They may also positively affect both teachers' prevalent emotions and instructional behaviours, thereby weakening statistical relations between individual work enjoyment ratings and teaching characteristics.

A third, more speculative explanation lies in superior capabilities of teachers in social classes to effectively regulate their emotions and thus, provide stimulating, supportive and application-oriented lessons irrespective of how much they truly enjoy their professional practice. Interview studies in which teachers talk about effectively up-regulating their emotions to create a positive, productive and inspiring classroom atmosphere bolster this interpretation (Sutton et al. 2009). Future studies may therefore include emotion regulation strategies (Gross and Thompson 2007) and self-control (Bertrams et al. 2013) to examine some of the complex individual boundary conditions of emotional crossover. The present study confined itself to contextual moderators in a very first attempt to investigate crossover in vocational classrooms.

Since the design of our study does not allow controlling for students' enjoyment levels at the beginning of the school year, definite causal inferences are difficult to draw. However, because questionnaire data were collected from different perspectives and at different points in time, our results are less subject to common source bias than studies that solely rely on either teacher self-reports or student ratings (Frenzel 2014).

A modest sample size at level 2 (77 classes) impairs the measurement model fit of teachers' work enjoyment, but using manifest variables to avoid these constraints would have simply ignored measurement errors. Teaching characteristics even entered the models by using a doubly latent approach of measurement (Marsh et al. 2009), which enabled us to control for both measurement and sampling errors. Still, although 77 classes are a considerable number in non-funded studies like the present one, further investigations should try to collect data from at least 120-150 classes (Little 2013, 199 et seq.). They might also complement student ratings by ratings of trained observers.

Finally, although we could demonstrate varying strengths of positive associations between teaching characteristics and students' enjoyment of lessons across different domains of initial vocational training (while ensuring measurement invariance of the relevant constructs), we cannot yet infer why this is the case. Future studies should therefore attend to varying expectations, needs, empathetic abilities, or even affiliative intents (Hess and Fischer 2013) among differing target groups of vocational education. Again, this implies extending our approach of examining emotional crossover by including not only context-specific but also person-specific moderators.

\section{Conclusion}

In the present study, emotional crossover from vocational teachers to their students could be statistically established only in classes preparing for commercial occupations. Nevertheless, consistently positive relationships between investigated teaching 
characteristics and student ratings of enjoying the lessons reliably appear across all commercial, social and technical classes (although with varying strengths). Thus, we encourage vocational education researchers to further develop coherent instructional designs that promote communicative clarity, individualized support, stimulation and application-orientation, preferably simultaneously, to exploit the benefits of positive activity-related emotions for student learning that were outlined at the beginning of this paper.

Relations between teachers' work enjoyment and observable teaching characteristics were not as consistent as expected when comparing teachers for different occupational fields. In the social domain, teachers were found to provide clarity and support, stimulation and application-orientation irrespective of their reported enjoyment levels. This finding should encourage researchers to use more fine-grained instruments to distinguish enjoyment ratings for various elements of teachers' professional practice (rather than work in general) but also to examine the functional relevance of teachers' regulative capabilities in dealing with emotional experiences in their professional lives.

\section{Additional file}

Additional file 1: Table SA. Measurement Invariance Test for the Moderator "Type of Training". Table SB. Measurement Invariance Test for the Moderator "Domain of Training". Table SC. Mediation and Moderated Mediation Models - Model fit indices. Table SD. Mediation and Moderated Mediation Models -Coefficients and P-values. Table SE.

Scale items used in the present study.

Authors' contributions

Both authors contributed substantially to this work. JW designed the study and handled the data collection. JW developed the theoretical framework in consultation with $\mathrm{CH}$. CH ran statistical analyses in consultation with JW. Both authors structured, wrote and revised the manuscript at all stages. Both authors read and approved the final manuscript.

\section{Author details}

${ }^{1}$ Chair of Business Education and Educational Management, University of Bamberg, Kärntenstr. 7, 96052 Bamberg, Germany. ${ }^{2}$ Department of Educational Research, Johannes Kepler University of Linz, Altenberger Straße 69, 4040 Linz, Austria.

\section{Acknowledgements}

We would like to thank Timo Gnambs (Leibniz Institute for Educational Trajectories, Bamberg, Germany), Christoph Weber (Teacher Training Institute, Linz, Austria), and Alexander Robitzsch (Leibniz Institute for Education in Science and Mathematics, Kiel, Germany) for valuable statistical advice.

\section{Competing interests}

The authors declare that they have no competing interests. The manuscript has not been submitted for publication or published elsewhere.

\section{Availability of data and materials}

Please contact the first author for further details on the data set.

Consent to participate

All participants are older than 16 years. Participation was voluntarily.

Ethics approval

The study and data collection was carried out in accordance with the ethical guidelines of University of Bamberg.

\section{Publisher's Note}

Springer Nature remains neutral with regard to jurisdictional claims in published maps and institutional affiliations. 


\section{References}

Ahmed W, Van der Werf G, Kuyper H, Minnaert A (2013) Emotions, self-regulated learning, and achievement in mathematics: a growth curve analysis. J Educ Psychol 105(1):150-161

Ainley M, Ainley J (2011) Student engagement with science in early adolescence: the contribution of enjoyment to students' continuing interest in learning about science. Contemp Educ Psychol 36(1):4-12

Aziz Q, Thompson DG, Ng VWK, Hamdy S, Sarkar S et al (2000) Cortical processing of human somatic and visceral sensation. J Neurosci 20(7):2657-2663

Bakker AB, Westman M, van Emmerik IJH (2009) Advancements in crossover theory. J Manag Psychol 24(3):206-219

Becker ES, Goetz T, Morger V, Ranellucci J (2014) The importance of teachers' emotions and instructional behavior for their students'emotions-an experience sampling analysis. Teach Teach Educ 43:15-26

Bertrams A, Englert C, Dickhäuser O, Baumeister RF (2013) Role of self-control strength in the relation between anxiety and cognitive performance. Emotion 13(4):668-680

BIBB-Bundesinstitut für Berufsbildung (2016) Bekanntmachung des Verzeichnisses der anerkannten Ausbildungsberufe und des Verzeichnisses der zuständigen Stellen. https://www.bibb.de/dokumente/pdf/verzeichnis_anerk_ berufe_2016_bibb.pdf. Accessed 16 Nov 2016

Bieg M, Goetz T, Hubbard K (2013) Can I master it and does it matter? An intraindividual analysis on control-value antecedents of trait and state academic emotions. Learn Individ Differ 28:102-108

Bieg M, Goetz T, Lipnevich AA (2014) What students think they feel differs from what they really feel-academic selfconcept moderates the discrepancy between students'trait and state emotional self-reports. PLoS ONE 9(3):1-9

Brophy J (2008) Developing students' appreciation for what is taught in school. Educ Psychol 43(3):132-141

Buff A, Reusser K, Rakoczy K, Pauli C (2011) Activating positive affective experiences in the classroom: "Nice to have" or something more? Learn Instr 21(3):452-466

Chartrand TL, Maddux WW, Lakin JL (2005) Beyond the perception-behavior link: the ubiquitous utility and motivational moderators of nonconscious mimicry. In: Hassin RR, Uleman JS, Bargh JA (eds) The new unconscious. Oxford University Press, New York, pp 334-361

Chen FF (2007) Sensitivity of goodness of fit indexes to lack of measurement invariance. Struct Equ Model 14:464-504

Cheung GW, Rensvold RB (2002) Evaluating goodness-of-fit indexes for testing measurement invariance. Struct Equ Model 9:233-255

Cohen J (1988) Statistical power analysis for the behavioral sciences. Taylor \& Francis Group, New York

De Bruijn E, Leeman Y (2011) Authentic and self-directed learning in vocational education: challenges to vocational educators. Teach Teach Educ 27(4):694-702

Deissinger T (2007) "Making schools practical": practice firms and their function in the full-time vocational school system in Germany. Educ Train 49(5):364-379

Deissinger T, Hellwig S (2005) Apprenticeship in Germany: modernising the dual system. Educ Train 47(4/5):312-324

Eder F (2006) Interessen und bewältigung der schule. In: Haider G, Schreiner C (eds) Die PISA-studie. Österreichs Schulsystem im internationalen Wettbewerb. Böhlau, Vienna, pp 270-279

Ellsworth PC, Scherer KR (2003) Appraisal processes in emotion. In: Davidson RJ, Goldsmith H, Scherer KR (eds) Handbook of affective sciences. Oxford University Press, New York, pp 572-595

Fredrickson BL, Branigan C (2005) Positive emotions broaden the scope of attention and thought-action repertoires. Cogn Emot 19(3):313-332

Frenzel AC (2014) Teacher emotions. In: Pekrun R, Linnenbrink-Garcia L (eds) International handbook of emotions in education. Routledge, New York, pp 494-519

Frenzel AC, Goetz T, Lüdtke O, Pekrun R, Sutton RE (2009a) Emotional transmission in the classroom: exploring the relationship between teacher and student enjoyment. J Educ Psychol 101(3):705-716

Frenzel AC, Goetz T, Stephens EJ, Jacob B (2009b) Antecedents and effects of teachers' emotional experiences: an integrated perspective and empirical test. In: Schutz PA, Zembylas M (eds) Advances in teacher emotion research: the impact on teachers'lives. Springer, Heidelberg, pp 129-151

Gläser-Zikuda M, Fuß S, Laukenmann M, Metz K, Randler C (2005) Promoting students' emotions and achievementinstructional design and evaluation of the ECOLE-approach. Learn Instr 15(5):481-495

Goetz T, Hall NC, Frenzel AC, Pekrun R (2006) A hierarchical conceptualization of enjoyment in students. Learn Instr 16(4):323-338

Goetz T, Cronjaeger H, Frenzel AC, Lüdtke O, Hall NC (2010) Academic self-concept and emotion relations: domain specificity and age effects. Contemp Educ Psychol 35(1):44-58

Goetz T, Lüdtke O, Nett UE, Keller MM, Lipnevich AA (2013) Characteristics of teaching and students' emotions in the classroom: investigating differences across domains. Contemp Educ Psychol 38(4):383-394

Gross JJ, Thompson RA (2007) Emotion regulation: conceptual foundations. In: Gross JJ (ed) Handbook of emotion regulation. Guilford Press, New York, pp 3-24

Hagenauer G, Hascher T (2010) Learning enjoyment in early adolescence. Educ Res Eval 16(6):495-516

Härtel CEJ, Page KM (2009) Discrete emotional crossover in the workplace: the role of affect intensity. J Manag Psychol 24(3):237-253

Hascher T (2010) Learning and Emotion: perspectives for theory and research. Eur Educ Res J 9(1):13-28

Hatfield E, Bensman L, Thornton PD, Rapson RL (2014) New perspectives on emotional contagion: a review of classic and recent research on facial mimicry and contagion. Interpersona 8(2):159-179

Helm C (2015) Reziproke Effekte zwischen wahrgenommenem Lehrerverhalten, intrinsischer Motivation und der Schülerleistung im Fach Rechnungswesen. AMS Rep 111:1-36

Hess U, Fischer A (2013) Emotional mimicry as social regulation. Personal Soc Psychol Rev 17(2):142-157

Hoeckel K, Schwartz R (2010). Learning for jobs. OECD reviews of vocational education and training. Germany. Organisation for economic co-operation and development (OECD). https://www.oecd.org/germany/45668296.pdf. Accessed 30 Nov 2016

Hu L, Bentler PM (1999) Cutoff criteria for fit indexes in covariance structure analysis: conventional criteria versus new alternatives. Struct Equ Model A Multidiscip J 6(1):1-55 
Isen AM (2008) Some ways in which positive affect influences decision making and problem solving. In: Lewis M, Haviland-Jones J, Feldman Barrett L (eds) Handbook of emotion, 3rd edn. Guilford Press, New York, pp 548-573 Izard CE (1977) Human emotions. Plenum Press, New York

Johnston L, Miles L, Macrae CN (2010) Why are you smiling at me? Social functions of enjoyment and non-enjoyment smiles. Br J Soc Psychol 49(1):107-127

Keller MM, Goetz T, Becker ES, Morger V, Hensley L (2014) Feeling and showing: a new conceptualization of dispositional teacher enthusiasm and its relation to students' interest. Learn Instr 33:29-38

Knöll B, Gschwendtner T, Nickolaus R, Ziegler B (2007) Motivation in der elektrotechnischen Grundbildung. Zeitschrift für Berufs- und Wirtschaftspädagogik 103(3):397-415

Kreibig SD (2010) Autonomic nervous system activity in emotion: a review. Biol Psychol 84(3):394-421

Kunter M, Holzberger D (2014) Loving teaching: research on teachers'intrinsic orientations. In: Richardson PW, Karabenick SA, Watt HMG (eds) Teacher motivation. Theory and practice. Taylor \& Francis, New York, pp 83-99

Kunter M, Tsai YM, Klusmann U, Brunner M, Krauss S, Baumert J (2008) Students' and mathematics teachers' perceptions of teacher enthusiasm and instruction. Learn Instr 18(5):468-482

Levine LJ, Lench HC, Safer MA (2009) Functions of remembering and misremembering emotion. Appl Cogn Psychol 23(8):1059-1075

Little T (2013) Longitudinal Structural Equation Modeling. The Guilford Press, New York

Lüdtke O, Robitzsch A, Trautwein U, Kunter M (2009) Assessing the impact of learning environments: how to use student ratings of classroom or school characteristics in multilevel modeling. Contemp Educ Psychol 34:120-131

Marsh HW, Lüdtke O, Robitzsch A, Trautwein U, Asparouhov T, Muthén BO, Nagengast B (2009) Doubly-latent models of school contextual effects: integrating multilevel and structural equation approaches to control measurement and sampling errors. Multivar Behav Res 44(6):764-802

Meyer DK (2014) Situating emotions in classroom practices. In: Pekrun R, Linnenbrink-Garcia L (eds) International handbook of emotions in education. Routledge, New York, pp 458-472

Muthén LK, Muthén BO (1998-2014) Mplus user's guide. (Version 7). Muthén \& Muthén, Los Angeles

Pekrun R, Stephens EJ (2010) Achievement emotions: a control-value approach. Soc Pers Psychol Compass 4(4):238-255

Pekrun R, Götz T, Titz W, Perry RP (2002) Positive emotions in education. In: Frydenberg E (ed) Beyond coping: meeting goals, visions, and challenges. Oxford University Press, Oxford, pp 149-173

Pekrun R, Frenzel A, Goetz T, Perry RP (2007) The control-value theory of achievement emotions: an integrative approach to emotions in education. In: Schutz PA, Pekrun R (eds) Emotion in education. Academic Press, San Diego, pp 13-36

Putwain D, Sander P, Larkin D (2013) Academic self-efficacy in study-related skills and behaviours: relations with learningrelated emotions and academic success. Br J Educ Psychol 83(4):633-650

Ranellucci J, Hall NC, Goetz T (2015) Achievement goals, emotions, learning, and performance: a process model. Motiv Sci 1(2):98-120

Reyes MR, Brackett MA, Rivers SE, White M, Salovey P (2012) Classroom emotional climate, student engagement, and academic achievement. J Educ Psychol 104(3):700-712

Scherer K (2005) What are emotions? And how can they be measured? Soc Sci Inf 44(4):695-729

Seifried J, Sembill D (2005) Emotionale Befindlichkeit in Lehr-Lern-Prozessen in der beruflichen Bildung. Zeitschrift für Pädagogik 51(5):656-672

Sembill D, Wuttke E, Seifried J, Egloffstein M, Rausch A (2007) Selbstorganisiertes Lernen in der beruflichen Bildung Abgrenzungen, Befunde und Konsequenzen. Berufs- und Wirtschaftspädagogik online, 13. http://www.bwpat.de/ ausgabe13/sembill_etal_bwpat13.pdf. Accessed 15 Dec 2016

Stride CB, Gardner SE, Catley N, Thomas F (2015) Mplus code for mediation, moderation and moderated mediation models (1-80). http://www.figureitout.org.uk. Accessed 08 Dec 2016

Sutton RE, Mudrey-Camino R, Knight CC (2009) Teachers' emotion regulation and classroom management. Theor Into Pract 48(2):130-137

Sy T, Côté S, Saavedra R (2005) The contagious leader: impact of the leader's mood on the mood of group members, group affective tone, and group processes. J Appl Psychol 90(2):295

Titsworth S, McKenna TP, Mazer JP, Quinlan MM (2013) The bright side of emotion in the classroom: do teachers' behaviors predict students' enjoyment, hope, and pride? Commun Educ 62(2):191-209

Valiente C, Swanson J, Eisenberg N (2012) Linking students' emotions and academic achievement: when and why emotions matter. Child Dev Perspect 6(2):129-135

Westman M (2006) Crossover of stress and strain in the work-family context. In: Jones F, Burke RJ, Westman M (eds) Worklife balance: a psychological perspective. Psychology Press, New York, pp 163-184

Wirtz D, Kruger J, Scollon CN, Diener E (2003) What to do on spring break? The role of predicted, on-line, and remembered experience in future choice. Psychol Sci 14(5):520-524 